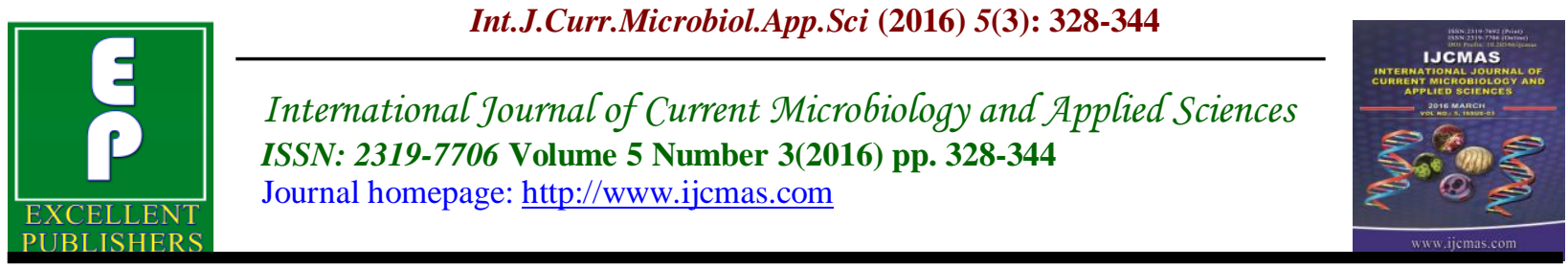

Review Article

http://dx.doi.org/10.20546/ijcmas.2016.503.040

\title{
Role of Probiotics in human health and disease: An update
}

\author{
Sameer Singh Faujdar*, Priya Mehrishi, Surabhi Bishnoi and Amisha Sharma \\ Department of Microbiology, Maharishi Markandeshwar Medical College and Hospital, \\ Kumarhatti, Solan, Himachal Pradesh, 173229, India \\ *Corresponding author
}

\begin{abstract}
A B S T R A C T
Keywords

Probiotics in human health and disease

Article Info

Accepted:

15 February 2016

Available Online:

10, March 2016

Probiotics are live bacteria and yeasts that are good for our health, especially our digestive system. We usually think of bacteria as something that causes diseases. But our body is full of bacteria, both good and bad. Probiotics are often called "good" or "helpful" bacteria because they help keep our gut healthy. Probiotics are naturally found in our body. We can also find them in some foods and supplements. It's only been since about the mid-1990s that people have wanted to know more about probiotics and their health benefits. Doctors often suggest them to help with digestive problems. And because of their newfound fame, we can find them in everything from yogurt to chocolate. Researchers are trying to figure out exactly how probiotics work. Here are some of the ways they may keep us healthy: When we lose "good" bacteria in our body (like after you take antibiotics, for example), probiotics can help replace them. They can help balance our "good" and "bad" bacteria to keep our body working like it should.
\end{abstract}

\section{Introduction}

The world as we have created it is a process of our thinking. It cannot be changed without changing our thinking- Albert Einstein. About 2000 years ago, Hippocrates quoted that "Let food be the medicine and medicine be the food" is certainly the tenet of today (Sumit N et al., 2011). Currently there is an increased global interest due to the recognition that 'neutraceuticals' play a major role in health enhancement. The term "nutraceutical" was coined by combining the terms "Nutrition" and "Pharmaceutical" in 1989 by Dr. Stephen DeFelice, Chairman of Foundation for Innovation in Medicine. It can be defined as a food or nutrient, which provides health benefits, including the prevention and treatment of a disease, like joint problems, cardiovascular health, eye related problems and cancer prevention, such foods are commonly are referred to as 'functional foods', signifying they are /or their components may provide health benefit beyond basic nutrition. Nutraceuticals contain health promoting ingredients or natural components that have a potential health benefit for the body (Table 1). Eastern cultures have a long history of use of traditional medicines associated with health foods in the form of recognized nutritional foods, food supplements, medicinal herbs and crude powdered drugs derived from plants, animals, marine sources. India and China are known for their 
production of traditional functional food products and nutraceuticals. There is an exhaustive list, about 470 nutraceutical and functional food products are available in various combinations and it is growing day by day (Rajasekaran A et al., 2008). In present review, we have tried to focus on the role of probiotics in health in general and oral health in particular.

\section{Historical Perspectives}

Looking back through history, however one has forgotten the concept of using live bacteria called probiotics, beneficial to health has been resurrected and has now come under intensive research using modern study designs and methods (Esha A et al., 2011). The most common problem prevailing in the field of medicine is the development of resistance to a range of antibiotics by some important pathogens. The promiscuous and heady use of antibiotics has led to the emergence of multi-resistant strains of bacteria. This unfortunate development has led scientists to shift the paradigm of treatment from specific bacteria elimination to altering bacterial ecology by use of probiotics (Vishnu HP 2012). There is a long history of health claims concerning living microorganisms in food, particularly lactic acid bacteria. In a Persian version of the Old Testament it states that "Abraham owed his longevity to the consumption of sour milk". In $76 \mathrm{BC}$, the Roman historian Plinius recommended the administration of fermented milk products for treating gastroenteritis. Elie Metchnikoff was perhaps the first researcher to propose that fermented dairy products have beneficial properties. Although there is reference to sour milk or fermented cultures as far back as the Bible, Elie Metchnikoff is regarded as the grandfather of modern probiotics. Elie Metchnikoff proposed that the regular consumption of lactic acid bacteria in fermented dairy products, such as yogurt, was associated with enhanced health and longevity in Bulgarian peasant populations. Grigorov later demonstrated how healthy bacteria in yogurt helped digestion and improved the immune system. He asserted that some of the bacterial organisms present in the large intestine were a source of 'toxicants', toxic substances that contributed to illness and ageing. He suggested that "The dependence of the intestinal microbes on the food makes it possible to adopt measures to modify the flora in our bodies and to replace the harmful microbes by useful microbes." To test the hypothesis on the health benefit of consuming lactic acid bacteria, Metchnikoff drank sour milk every day until his demise at the ripe age of 71 in 1916. The concept of probiotics was thus born and a new field of microbiology was opened (Jaddu Jyothirmai R et al., 2010, Kingsley C et al., 2007).

\section{Prebiotics and Probiotics}

Prebiotics are the substances which reach the colon in the intact form are given to the animals and beneficial for microbial growth in the intestine and normal digestion process. They act as fertilizer for probiotics for example: insulin, fructooligosaccharides. Prebiotic was first discovered by Gibson and Roberfroid in 1995 defined generally as a "Non-digestible food ingredients that beneficially affect the host by selectively stimulating the growth activity of one or a limited number of bacterial species already established in the colon", and thus improving the host health (Nicole MR et al., 2000). More specifically, prebiotics are short-length carbohydrates, such as fructo oligosaccharides, gluco oligosaccharides and inulin that resists digestion in upper gastrointestinal tract and fermented in the colon to produce short-chain fatty acids, 
such as acetate, butyrate and propionate, which have positive effects on colonic cell growth and stability; (Pradeep $\mathrm{K}$ et al., 2012, Vineet A et al., 2012) whereas, the synergistic combinations of both pro and prebiotics are called Synbiotics as this approach includes a food or food supplement having both live cells of the beneficial bacteria and the selective substrate and the beneficial bacterial cells grow faster and competitively because of the presence of selective substrate and establish their predominance (Prashanthi $\mathrm{R}$ et al., 2011, Schrezenmeir J et al., 2001).

The term 'probiotic' is derived from the Latin preposition pro ('for') and the Greek adjective (biotic), the latter deriving from the noun (bios, 'life'). Today, two main definitions are used. According to a WHO/FAO report (2002), probiotics are "Live microorganisms which, when administered inadequate amounts, confer a health benefit on the host". International Life Science Institute (ILSI) Europe suggests a definition according to which a probiotic is "A live microbial food ingredient that, when ingested in sufficient quantities, exerts health benefits on the consumer. Probiotics are live microorganisms, basically bacteria that when ingested in adequate amounts would confer health benefit beyond the basic nutrition (Vineet A et al., 2012). They are extensively studied for their health promoting effects because they repopulate the beneficial bacteria which can help to kill pathogenic bacteria and fight against infection (Kedar S et al., 2010). Traditionally, probiotics have been associated with gut health as there is a presence of greatest concentration of commensal organisms spread over more than $400 / \mathrm{m}^{2}$ of surface area. The gut flora is required rapidly just after birth and remains stable throughout the life (Bhuwaneshwari J et al., 2012). They are also called "friendly bacteria" or "good bacteria as supported by an increasing number of in vitro and in vivo experiments using conventional and molecular biologic methods (Rinkee $\mathrm{M}$ et al., 2011).

Many microbial types are used around the world to ferment milk, plant food, meat and other products. However, much progress has been made since in terms of the fermentation of dairy products. In this regard most probiotics fall into categories of lactic acid-producing bacterial organisms, including Lactobacillus and Bifidobacterium, but also non-lactic acid organisms (Table-2). Probiotics are most often incorporated in yogurt and fermented milk, but other food lines are now available and numerous products are sold in tablet, capsule, and powder.

\section{Lactobacillus Species}

Ubiquitous in nature, found in carbohydrate rich environment. They are gram positive spore forming, catalase negative appearing as rods or coccobacilli, fermentative, microaerophillic and chemo organotrophic, helpful in the production of enzymes which digest and metabolize proteins or carbohydrates, synthesize vitamin B complex, vitamin $\mathrm{K}$ and facilitate breakdown of bile salts. More than 100 species are identified and use in the form of gel, paste, powder and liquid forms (Patil MB et al., 2006, Meurman JH 2005).

\section{Bifidobacterium Species}

This species were $1^{\text {st }}$ isolated and visualized by Tissier (1990) from the feces of breast feed neonates. They are strictly anaerobic, rods shaped and predominate in the large intestine. Over 30 species have been identified. They metabolize lactose, generate 
lactic ions from lactic acid and synthesize vitamins. They also ferment indigestible carbohydrates and produce beneficial short chain fatty acids. (Galdeano CM et al., 2007, Nicole MR et al., 2000)

\section{Streptococcus Thermophilus and Lactobacillus Bulgaricus}

Are primary cultures used in yogurt production. Most noted benefits are to metabolize lactose, improve lactose intolerance and antimicrobial activity (Soccol C R et al 2010)

\section{Saccharomyces Boulardii}

It is a non-colonizing lactic acid producing yeast. Most noted feature is that they secrete proteases and other substances that breakdown bacterial enterotoxins and inhibit their binding to intestinal receptors. They also enhance vitamin production and reduce serum cholesterol level (Kedar $\mathrm{S}$ et al., 2010).

Following are the requirements which have been identified for a microorganism to be defined as an effective probiotic. (Azizpour K et al., 2009, Behnsen J et al., 2013)

The probiotic should exert positive effects on the host. It should be acid resistant, bile resistant and contain a minimum $30 \times 10^{9}$ CFU/ Gram.

The probiotic should possess high survival rate \& multiply faster

The adhesive capability of probiotics must be firm and faster.

Exclude or reduce pathogenic adherence.
Produce acids, peroxide and bacteriocins, antagonistic for the growth of pathogens.

Safe, noninvasive, non-carcinogenic and non-pathogenic.

Coaggregate to form a normal balanced flora.

Probiotics should be durable enough to withstand the duress of commercial manufacturing, processing, packing and distribution so it can be delivered alive to the intestine.

\section{Mechanisms of Action of Probiotics}

(Narwal A et al., 2011, Tiwari G et al., 2012, Calafiore A et al., 2012, Rastogi P et al., 2011, Kumar A et al., 2013)

Compete for nutrients and growth factors.

Produces antimicrobial compounds like hydrogen peroxide, bacteriosin, organic acids and dipicolinic acid which inhibits the growth of pathogenic bacteria.

Compete for the adhesion sites.

Modifies microbial population by biofilm formation.

Alter the host immune response by increase IL-10, TGF- $\beta$, decrease TNF- $\alpha$ and increase the IgA production.

Decreases production of inflammation associated molecules.

Prevents cytokines induced apoptosis.

Balances the gut and oral microbial flora thus making its colonization resistant to pathogenic bacteria. 
Increases the calcium and other minerals absorption.

Modifies the structure and function of intestinal epithelium and improves the barrier function.

Inhibits the growth of pathogenic enteric bacteria by decreasing luminal ph.

Lowers the toxigenic and mutagenic reaction by its metabolic product.

Increase the turnover of enterocytes by production of butyric acid.

\section{Probiotics in Oral Health and Disease}

Dental caries is a multifactorial disease of bacterial origin that is characterized by acid demineralization of the tooth enamel. Streptococcus mutans is the main microorganisms involved in causation of dental caries (Singh VP et al., 2013). Probiotics can reduce the risk for a high $\mathrm{S}$. mutans level occurrence. Bacteria administered as probiotic compete with carcinogenic microbes for adhesion sites as well as for nutrients and growth factors leading to reduced level of S. mutans in oral cavity. Streptococcus thermophilus and lactobacillus species were the only ones with the capacity to integrate into a biofilm present on a hydroxyapatite surface and to interfere with development of the carcinogenic species Streptococcus sobrinus. L. rhamnosus $G G$ and L. reuteri can inhibit colonization by streptococcal carcinogenic pathogens and therefore reduce tooth decay incidence in children (Kedar S et al., 2010). Nikawa et al., 2004 reported that consumption of yogurt containing $\mathrm{L}$. reuteri over a period of 2 weeks reduced the concentration of $S$. mutans in saliva by up to $80 \%$. Cagler et al., in a comparative study of S. mutans reduction effects by several probiotic administration forms showed a reduced $\mathrm{S}$. mutans level in patients receiving fluid or tablet in probiotic forms (FlichyFernández AJ et al., 2010). More recently, it was demonstrated that isolates of $W$. cibaria had the capacity to inhibit, both in vivo and in vitro, biofilm formation by $S$. mutans to prevent proliferation of this bacterial strain (Kang MS et al 2006). These promising results suggest a potentially beneficial application of probiotics for prevention of dental caries.

Periodontal diseases can be classified into two types such as gingivitis and periodontitis. Gingivitis is characterized by inflammation limited to the unattached gingiva, whereas periodontitis is a progressive, destructive disease that affects all supporting tissues of teeth, including the alveolar bone (Houle MA et al., 2003). The main pathogenic agents associated with periodontitis are $P$. gingivalis, T. denticola, $T$. forsythia, and A .actinomycetemcomitans. These bacteria have a variety of virulent characteristics allowing them to colonize the sub gingival sites, escape the host defense system and cause tissue damage (Rinkee M et al., 2011). In a Russian study using probiotic tablets in complex treatment of gingivitis and different degrees of periodontitis, the effect of probiotics to the normalization of microflora was found to be higher in comparison to the controls, particularly in the cases of gingivitis and periodontitis. A decrease in gum bleeding and reduced gingivitis has been observed with the application of $L$. reuteri. Probiotics strains included in periodontal dressings at optimal concentration were shown to diminish the number of most frequently isolated periodontal pathogens like Bacteriodes species, Actinomyces species and Staphylococcus intermedius and Candida albicans (Jaddu Jyothirmai R et al., 2010).Patients with various periodontal 
diseases, gingivitis, periodontitis, and pregnancy gingivitis, were locally treated with a culture supernatant of a L. acidophilus strain. Since the primary etiological factors for the development of periodontal disease are bacteria which are present in supra and sub gingival biofilm. Patients with periodontal disease who used chewing gum or lozenges containing probiotics saw their periodontal status improve (Singh VP et al., 2013).

Halitosis or bad breath is a condition that affecting comparatively large section of population with multiple local and systemic etiological factors. The main local etiologies include periodontitis, poor oral hygiene, deep dental caries, tongue coating and faulty restorations. Bad breath in oral cavity in mainly ascribed to the production of volatile sulfur compounds (VSC) by gram negative and gram positive anaerobes residing in periodontal pockets and on the dorsal surface of tongue. The replacement of bacteria implicated in halitosis by colonization with probiotic bacterial strains may have potential application as adjuncts for the prevention and treatment of halitosis (Pradeep K et al., 2012). A definite inhibitory effect on the production of VSC by $F$. nucleatum was observed after ingestion of $W$. cibaria both in vitro and in vivo. In children, a marked reduction in the levels of $\mathrm{H}_{2} \mathrm{~S}$ and $\mathrm{CH}_{3} \mathrm{SH}$ was registered after gargling with W.cibaria containing rinse (Jaddu Jyothirmai $\mathrm{R}$ et al., 2010). The possible mechanism in the VSC reduction is the hydrogen peroxide generated by W.cibaria that inhibits the proliferation of $\mathrm{F}$. nucleatum, S. salivarius also a possible candidate for an oral probiotic which has demonstrated inhibitory effect on VSC by competing for colonization sites with species causing an increase in levels of VSC. Strains used as probiotic for mouth and gut associated halitosis include E.coli
Nisle 1917, S. salivarius k 12, W. confusa isolates and a lactic acid forming bacterial mixture (Haukioja A 2010).

Oral candidiasis: Candida species are part of a commensal oral flora in about $50 \%$ of healthy subjects, but able to cause a clinically apparent lesion if the immune defenses were breached either on the local or systemic level and a leading cause of infection in oral cavity (Hatakka $\mathrm{K}$ et al., 2007). It is particularly common in the elderly and in immunocompromised patients. Hatakka et al., showed a reduction in the prevalence of $\mathrm{C}$. albicans in the elderly after consumption of probiotic cheese containing $\mathrm{L}$. rhamnosus $\mathrm{GG}$ in a randomized placebo controlled trial. A concomitant feature of the probiotic activity observed in this study was diminished risk of hypo salivation and the feeling of dry mouth of the subjects. Results obtained by Koll et al., when assessing the effects of various Lactobacillus strains in oral cavity were markedly different; most strains suppressed growth of periodontal pathogens, including A. actinomycetemcomitans (60 out of 67 tested strains); P. gingivalis (35 out of 42 strains); P. intermedia (26 out of 42 strains); and carcinogenic S. mutans (37 out of 67 strains). No inhibition was found for C. albicans growth (Flichy-Fernández AJ et al., 2010). The authors had no explanation to this and the finding certainly needs to be confirmed in further investigations.

\section{Treatment and Prevention of Diarrhoea by Probiotics}

Efficiency of the probiotics have been tested by a number of clinical trials for the prevention of acute diarrheal condition. Multiple short and long terms use of antibiotics leads to a common side effect of diarrhea. Two meta analyses (using strains Lactobacillus acidophilus, Lactobacillus 
rhamnosus strain GG, Lactobacillus bulgaricus and yeast Saccharomyces boulardii) could be used to prevent antibiotic associated dairrhoea. Major problem in paedatrics hospital is the nosocomial diarrhea and it is prevalent worldwide. Prophylactic uses of probiotics (Bifidobacterium bifidum, Streptococcus thermophiles and $\mathrm{L}$ rhamnosus starin GG) are useful especially for infants for the prevention of acute diarrhea (Cremonini $\mathrm{F}$ et al., 2002, Saavedra JM et al., 1994).

\section{Management of Lactose Intolerance by Probiotics}

Lactose malabsorption in adult population varies from 50\%-100\% in African, Asian and South American countries and 5\%-15\% in Northern European and American countries. Lactose digestion improvement by using bacteria as starter culture in yogurt (Lactobacillus delbrueckii subspecies bulgericus and $\mathrm{S}$. thermophilus) is well recognized due to the presence of bacterial enzyme beta- galactosidase (Kolars JC et al., 1984). Several human studies demonstrated better lactose digestion and absorption in subjects that consumed fresh yogurt (live yogurt cultures) in comparison with the consumption of pasteurized product (heat killed bacteria) (Dewit O et al., 1988).

\section{Anticancer Properties of Probiotics}

Several studies revealed the importance of probiotic therapy that inhibited transformation of procarcinogen to active carcinogens which further reduced the risk of colon cancer. Probiotics may also inactivate mutagenic compounds, producing antimutagenic compounds, suppressing the growth of pro- carcinogenic bacteria, reducing the absorption of mutagens from the intestine and enhancing immune function (Van't Veer $\mathrm{P}$ et al., 1989).
Enteropathogens such as E.coli and clostridium perferinges produce enzymes such as beta-glucuronidase, and nitroreductase. Beta - glucosidase can convert procarcinogens to proximate carcinogens.16. Bifidobacterium creates a bactericidal environmental for these putative enteropathogens as colonizing cells of Bifidobacterium produces lactic acid and lower the intestinal $\mathrm{pH}$ and therefore develops a favorable environment which modulates the bacterial enzymes. Purified bifidobacterial has cell wall antitumor activities and induces activation of phagocytes to destroy growing tumor cells (Sekine K et al., 1994). One of the earliest and most frequently occurring genetic alterations associated with human cancer, especially carcinoma of colon are associated with RAS activation. Elevated levels of ras P-21 have also been correlated with increased cell proliferations, histologic grade, nuclear aplasia and degree of undifferentiation.18 B.longum cultures as demonstrated by Reddy et al suppressed the expression of total and neonated ras $\mathrm{P}-21$ in the colonic mucosa and tumors compared with control diet. B. longum also plays a role as an immunomodulator and biological response modifier by providing an additional mechanism of tumor suppression. Probiotics also stimulate apoptosis through end-product formation (Reddy BS, Riverson A 1993, Okawa T et al., 1993).

\section{Immune Enhancement by Probiotics}

Evidences suggest that specific strains of lactic acid bacteria, when consumed in certain numbers, are able to modulate aspects of both natural and acquired immune responses. The colonic microflora affects mucosal and systemic immunity in the host. It is produced either by absorption of soluble antigen or by translocation of lactobacilli through the gut wall into the bloodstream. 
Lactobacilli which adhere to human intestinal epithelial cells are capable of activating macrophages .intestinal epithelial cells, blood leucocytes, $\mathrm{B}$ and $\mathrm{T}$ lymphocytes, and accessory cells of immune system are all complicated targets for probiotics (Berg RD 1983).

\section{Innate Immune Response and Probiotics}

The ability of specific strains of probiotics to enhance aspects of natural immunity in human subjects is well documented. Enhanced phagocytic capacity of peripheral blood leucocytes was reported by schiffrin and colleagues in healthy human adults administered fermented milk supplemented with specific strains of probiotics (Lactobacillus johymsonii Lal or bifidobacterium lactis Bb12) for three weeks. Cessation of probiotic consumption showed improvement in phagocytic activity which were sustained for several weeks and granulocytes showed higher increase in phagocytic cell function compared with monocytes. Subjects receiving probiotics have also been reported which have shown significant increase in the expression of receptors involved in phagocytosis (CR1, CR3 , FcyRI and Fc $\alpha$ R) In neutrophils, phagocytic index and oxidative burst or microbicidal capacity. It has also been observed that complement receptor expression are been influenced by different lactic acid bacteria strains which differ in their capacity in phagocytic cells. For example, He et al revealed that complement receptors were more efficiently upregulated by Lactobacillus lactis on blood leucocytes than $\mathrm{L}$ rhamnosus.76. Furthermore, dose of minimum $10^{9} \mathrm{cfu} /$ day was found to be necessary for the improvements in immune function as the immunostimulatory effect of probiotic intake was dose dependent (Schiffrin EJ et al., 1995, He F et al., 2000). Somehow ageing is also associated with a decline in immunocompetence as to correct the age related decline in phagocytic cells especially in the elderlies, supplementation with the probiotics could be used. Subjects receiving milk without probiotics had phagocytically less active leucocytes compared to the ones receiving milk containing L. rhamnosus (HN001) or B. lactis (HN019) for three to six weeks and exhibited significantly more phagocytically active blood leucocytes (neutrophils and monocytes). Simultaneously improvements and increase in the activity of $\mathrm{N} K$ cells in the peripheral blood of human volunteers fed with yogurt, milk, or sausages containing probiotics have also been reported (Gill HS et al 2001, Gill HS, Cross ML et al 2001).

\section{Humoral Immune Response and Probiotics}

Possible mechanisms of functioning of the immune system influenced by the probiotics are not fully understood. A large number of human studies have also shown that humoral immune response to natural infections and systemic or oral immunization is been potentiated by intake of specific strains of lactic acid bacteria. Lactobacillus $G G$ fed infants had significantly higher IgG, IgA and IgM IMMUNOGLOBULIN secreting cells compared to those given a placebo. Further it was also observed that $\operatorname{IgA}$ specific antibody secreting cells to rotavirus and serum IgA response was more efficiently stimulated by lactobacillus GG than L casei subspecies rhamnosus or a combination of $\mathrm{S}$ thermophilus and $\mathrm{L}$ delbruckii subspecies bulgaricus (Majamaa $\mathrm{H}$ et al., 1995). Immunogenecity of mucosal and systemic vaccines enhanced by the effect of probiotics has also been reported. Fourfold increase (0.04) in serum IgA antibody response to salmonella typhi immunization was reported by Link-Amster 
and colleagues in volunteers consuming yogurt containing $\mathrm{B}$. bifidum and $\mathrm{L}$ acidophilus La 1 compared with a 2.5 -fold increase in the control group (Link-Amster $\mathrm{H}$ et al., 1994). Pattern recognition receptors (such as toll like receptors) present on the surface of immunocompetent cells (monocytes, macrophages, dendritic cells, etc), present in the peyer's patches, lamina propria or other sites recognizes the probiotic associated molecular patterns (for example, peptidoglycan, lipotechoic acid, bacterial DNA) and triggers the release of a range of cytokines that shape the developing immune response or active immune response. Increased transport of antigenic materials across the gut and improved antigen presenting cell function (upregulation of antigen presenting molecules and co-stimulatory molecules induced by proinflammatory cytokines and/or increased B-cells) somehow potentiate humoral immune responses but the exact mechanism is not known (Gill HS 1998, Meydani SN, Ha WK 2000).

\section{Irritable Bowel Syndrome and Probiotics}

Bloating, flatulence, abdominal pain and diarrhea are common symptoms which are seen in patients with irritable bowel syndrome. These symptoms are difficult to treat and have a significant impact on lives of patients. Intestinal gas can produced by gut flora but they also consume gas and probiotics might reduce gas accumulation and improve the balance within the bowel.

Pain and flatulence in patients with irritable bowel syndrome is decreased by administration of a $\mathrm{L}$ plantarum strain in a double blind clinical trial. VSL\#3 probiotic mixtures is very useful for the relief of abdominal bloating in patients with diarrhea concluded in a recent placebo controlled trail. 28 patients with high volume diarrhea caused by food intolerance for 12 weeks administered $10^{10} \mathrm{cfu} / \mathrm{d}$ of Enterococcus faecium PR88 by Hunter et al and there was a symptomatic improvement in 19 of the 28 , and a significant decrease in faecal weight (Nobaek S et al., 2000, Kim HJ et al., 2003)

\section{Allergy and Probiotics}

Probiotics associated with disappearance of food allergy manifestation with decrease in concentration of $\operatorname{IgE}$ in the serum and with a lower frequency of allergies was reported by Loskutova et al and Trapp et al in two different studies (Loskutova IE 1985, Trapp CL et al., 1993). Inflammatory response in food allergy is alleviated by the potentiated effect of the probiotics on the nonimmunologic and immunologic defense barrier of the gut. Potentiate IgA response to potentially harmful antigens and $\operatorname{IgA}$ production in peyer's patches have been shown to be enhanced by Bifidobacteria and Lactobacilli (Yasui $\mathrm{H}$ et al., 1992). Secretion of Th2 cytokines which are IL4,IL-5,IL-6,IL-9, IL-10,IL-13 are reduced by the probiotics. Further these antigens are responsible for strong antibody (esp $\mathrm{IgG}$ and $\operatorname{IgE}$ ) responses and eosinophilia found in helminthic infections and allergic disorders (Sutas Y et al., 1996).

Efficacy of whey formula supplemented with Lactobacillus GG in infants with atopic eczema and cow's milk allergy was extensively examined by Majamaa and Isolauri and Significant improvement in clinical symptoms and markers of intestinal inflammation was seen in subjects receiving formula with Lactobacillus GG (Majamaa H et al., 1997). Immunomodulatory properties of native food protein modified by lactobacilli thus probiotics influenced the immune response of human by activation of lymphoid cells present in lymphoid tissues of gastrointestinal tract. 
Table.1 Classification of Nutraceuticals

\begin{tabular}{|c|l|l|}
\hline $\begin{array}{c}\text { S. } \\
\text { No }\end{array}$ & Class/Components & Sources \\
\hline $\mathbf{1}$ & $\begin{array}{l}\text { Probiotics/Prebiotics/ } \\
\text { Synbiotics }\end{array}$ & Curd, yogurt, Whole grains, onions. \\
\hline $\mathbf{2}$ & $\begin{array}{l}\text { Plant based } \\
\text { antioxidants } \\
\text { a. Polyphenol }\end{array}$ & $\begin{array}{l}\text { Fruits, Tea, babul pods, mustard cake, rape seed, salseed, Citrus, Fruits, } \\
\text { vegetables, soya bean. } \\
\text { Soyabean, GNC, Lucerne, chick pea } \\
\text { Soybean, flax, lentil seed, Maize, berseem, lucerne, Flax, rye, vegetables. } \\
\text { Berseem, lucerne, oat, maize fodder, carrots, vegetables, fruits, } \\
\text { Vegetables, Egg, Citrus, Corn. } \\
\text { Sunflower oil, Olive oil, Almond oil, Beet green, Spinach, Turnip. } \\
\text { Lemon, Orange, Rose hips, Papaya, Garlic. }\end{array}$ \\
\hline $\mathbf{3}$ & Omegatostrog 3 fatty acids & Milk \& meat, fish oil, berseem, maize, fodder, mustard, linseed, rapeseed \\
\hline $\mathbf{4}$ & Dietary fibers & Oats, Barley, Legumes, Carrot, Broccoli, Root Vegetables. \\
\hline
\end{tabular}

Table.2 Proven Probiotic Microorganisms

\begin{tabular}{|l|l|l|}
\hline \multicolumn{1}{|c|}{$\begin{array}{c}\text { Lactobacillus } \\
\text { Species }\end{array}$} & \multicolumn{1}{|c|}{$\begin{array}{c}\text { Bifidobacterium } \\
\text { Species }\end{array}$} & \multicolumn{1}{|c|}{ Non-lactic acid Species } \\
\hline L. rhamnosus GG (LGG) & B. lactis Bb 12 & Escherichia coli strain nissle \\
\hline L. rhamnosus GR-1 & B. infantis 35624 & Saccharomyces boulardiilyo \\
\hline L. reuteri RC-14 & B. breve strain Yakult & S. salivarius subsp. thermophilus \\
\hline L. casei DN114001 & B. animalis DN 117-001 & S. cremoris \\
\hline L. acidophilus LA-1 & B. lactis HN019 & S.intermedius \\
\hline L. reuteri SD2112 & B. longum BB536 & Leuconostoc \\
\hline L. plantarum 299v & B. bifidum & Pediococcus \\
\hline L. casei Shirota & B. thermophilum & Propionibacterium \\
\hline L. acidophilus LB & Bifidobacterium DN-17301 & W. cibaria \\
\hline L. rhamnosus HN001 & B. breve & E. faecium \\
\hline L. salivarius UCC118 & B. infantis & Lactococcus. lactis subsp. cremoris \\
\hline L. acidophilus NCFM & B. longum & S. diaacetylactis \\
\hline L. fermentum VRI003 & B. lactis & \\
\hline L. johnsonii Lj-1 & B. adolescentis & \\
\hline L. paracasei F19 & & \\
\hline L. sporogenes & & \\
\hline L.lactus & & \\
\hline L.cellobiosus & & \\
\hline L.brevis & & \\
\hline L.gasseri & & \\
\hline
\end{tabular}

Table references - (Esha A et al., 2011, Kingsley C et al., 2007, Nicole MR et al., 2000, Kedar S et al., 2010, Bhuwaneshwari J et al., 2012) 


\section{Lowering of Blood Cholesterol}

Consumption of fermented milk associated with reduced serum cholesterol level was reported by Mann and Spoerry (Mann GV, Spoerry A 1974). Mechanisms showing effect of probiotic on the cholesterol levels include assimilation of cholesterol by bacterial cells, deconjugation of bile acids by bacterial acid hydrolases, cholesterol binding to bacterial cell walls and inhibition of hepatic cholesterol synthesis and redistribution of plasma to the liver (Lovegrove J, Jackson K 2003). However studies in human subjects revealed conflicting results like reduction in serum cholesterol from 5.7 to $5.3 \mathrm{rmmol} / \mathrm{l}$ was reported by Lin et al after 7 weeks and in subjects receiving $\mathrm{L}$. acidophilus and $\mathrm{L}$. bulgaricus serum cholesterol reduced to $5.4 \mathrm{mmol} / 1$ after 16 weeks whereas the levels remain unchanged in the control subjects (Lin SY et al., 1989).

\section{Role of Probiotics in Bacterial Vaginosis and Urinary Tract Infections}

There is a high incidence of urogenital infections though antibiotics are generally effective. Microflora of the intestinal and urogenital tract have a central role in maintaining both the health and well - being of humans.

\section{Urinary Tract Infection}

Two strain combination for vaginal use was selected due to the extensive studies on the various lactobacilli strains. Combination comprises distal urethral L. rhamnosus GR1, primarily for its anti gram negative activities and resistance to spermicide and for anti gram -positive cocci activities, L. fermentum B-54 was replaced recently by RC-14 which was also responsible for hydrogen peroxide production. To formulate a good shelf life for patients, consistent doses are made as the gelatin capsule containing $10^{9}$ freeze dried organisms which is higher than the total microbial content of vagina.39.using one or two capsules vaginally per week reduced recurrence rates of UTI for a year with no side effects or yeast infections (Reid G et al., 1995).

\section{Bacterial Vaginosis}

Overgrowth of anaerobic organisms combined with a loss of protective lactobacilli is considered as bacterial vaginosis, normally it is found in the healthy vagina. Asymptomatic bacterial vaginosis reverted to normal lactobacilli in patients with the daily oral intake of probiotic strains Lactobacillus rhamnosus GR-1 and lactobacillus fermentum RC-14. Probiotic intake in patients suffering from vaginosis increases the lactobacillus count in vagina from rectal skin and enhancement of intestinal mucosal immunity effects vaginal immunity renders the environment less favourable to bacteria which are causing vaginosis (Reid G, Bruce AW et al., 2001, Reid G, Charbonnaeau D et al., 2003).

\section{Helicobacter Pyroli Infection and Probiotics}

Probiotics in Helicobacter pylori infection of the gastric mucosa has been tested as a new strategy. Growth of $\mathrm{H}$ pylori is known to be inhibited by some strains of lactic acid bacteria in vitro by several mechanisms (stimulating specific and non-specific immune responses and producing antimicrobial substances) and prevents infection (Wendakoon CN et al., 2002).

\section{Systemic Infection and Probiotics}

Immune system is boosted by translocation of viable or dead bacteria in minute 
amounts. Several complications have been shown to occur in several pathological conditions like sepsis, severe acute pancreatitis, liver cirrhosis and multi system failure by bacterial translocation due to bacterial translocation (Lichtman SM 2001). Sepsis is prevented in patients with severe acute pancreatitis with the use of probiotics. Patients treated with L. plantarum and incidence of pancreatic abscesses and necrosis were observed at a significant lower rate than in the control group in a randomized double blind trial (Olah A et al., 2002). Incidence of infection involving 95 liver transplant patients were further divided into 3 groups and submitted to different prophylaxis procedure: selective bowel decontamination with antibiotics, fermentable fibres with administration of live L. plantarum and the fibre supplement with the administration of heat killed $\mathrm{L}$. plantarum. 15 out of 32 patients $(48 \%)$ were recorded for postoperative infection in antibiotic group, 4 out of $31(13 \%)$ in the live L. plantarum group and in the heat killed L. plantarum group (34\%) that is 11 out of 32, being significant the difference between antibiotics and L. plantarum groups (Rayes N et al., 2002).

\section{Gut Microbiome and Aging}

Assembly of genomes from microorganisms inhabiting the gut is defined as the intestinal microbiome. Investigation of what gut microbes are actually doing can be done from faeces through a combination of metatranscriptomics, metaproteomics, and metabolomics approaches to analyze RNA, protein and small metabolite pools which are further identified by comparing against appropriate databases (Gosalbes M J et al., 2011, Marcobal A et al., 2013). Role of human microbiota in health and disease requires understanding of the cross talk between microbiota and host as well as integration of taxonomical and metabolic features. Dietary interventions effects on gut microbiota composition/functionality and host metabolic outcomes are provided through the basis of metabolomics but still there is a challenge to develop computational tools to integrate results from multiple levels (Franzosa E A et al 2014). Extremes of life in terms of microbiota modulation have not yet been taken into account for probiotic or prebiotic selection to date the specific needs of defined population. Specific and nutritionally adequate products are required to satisfy the particular requirements of these population groups. Development of a new generation of highly adapted functional food products should now be integrated or shared as knowledge.

\section{Risks Associated with Clinical use of Probiotics}

Endocarditis, liver abscess, pneumonia in adult and sepsis in children caused by Lactobacillus species are rare but well recognized in the absence of probiotic supplementation. It was also reported by Rautio et al in a 75 year old woman who developed Lactobacillus GG (LGG) liver abscess and pneumonia after 4 months due to daily consumption of LGG (Rautio M et al., 1999). Similarly Mackay et al reported the case of a 67 yr old man who suffered from L. rhamnosus endocarditis after a dental extraction by taking probiotic capsules daily (Mackay AD et al., 1999).

Many cases of probiotic bacteremia or fungemia have occurred in patients with underlying immune compromise, chronic disease, or debilitation, and no reports have described sepsis related to probiotic use in otherwise healthy persons. Most cases of probiotic sepsis have resolved with appropriate antimicrobial therapy, but in 
some cases patients have developed septic shock (Hennequin C et al., 2000).

\section{Conclusion and Future Prospective}

There is no doubt that we will witness a significant increase in the role of probiotics in nutrition and medicine over the next decades. Their application in the prevention and treatment of various disorders should be considered by medical professionals as well as should be promoted by the food industry. Newly developed probiotic strains should be thoroughly evaluated for safety before being marketed. Although much remains to be learned regarding the mechanisms of action and the appropriate administration of probiotic strains, it is clear that different strains can have very specific effects. Moreover their effects may vary in health and disease, in different disease states, and in different age groups. Thus, clinical trial results from one probiotic strain in one population cannot be automatically generalized to other strains or to different populations. Further studies are needed to explore mechanistic issues and probiotic interactions. In view of the increasing use of probiotics as health supplements and therapeutic agents, clinicians need to be aware of the risks and benefits of these treatments.

\section{References}

Azizpour K, Bahrambeygi S, Azizpour A (2009). History and Basic of Probiotics. Res J boil sci; 4:409-426.

Behnsen J, Deriu E, Sassone-Corsi M, Raffatellu M 2013. Probiotics: properties, examples, and specific applications. Cold Spring Harb Perspect Med 3:a010074. doi:.10.1101/cshperspect.a010074

Berg RD (1983). Translocation of indigenous bacteria from the intestinal tract, In: ed Hentges DJ, Human intestinal Microflora in health and diseases; New York; Academic Press 333-52.

Bhuwaneshwari J, Ramya V, Manisunder, Preethi (2012). Probiotics and its implications in periodontal TherapyA review. IOSR J Dental and Med Sci; 2(5):11-15.

Calafiore A, Gionchetti P, Calabrese C, Tambasco R, Fornarini G.S, Liguori G, Riso D, Campieri M, Rizzello F (2012). Probiotics, Prebiotics and Antibiotics in the Treatment of Inflammatory Bowel

Disease. Journal of

Gastroenterology and Hepatology Research; 1(6): 97-106.

Cremonini F, Di Caro S, Nista EC, et al., (2002). Meta-analysis: the effect of probiotic administration on antibiotic-associated diarrhoea. Aliment Pharmacol Ther; 16:14617.

Dewit O, Pochart P, Desjeux J-F (1988). Breath hydrogen concentration and plasma glucose, insulin and free fatty acid levels after lactose, milk, fresh or heated yogurt ingestion by healthy young adults with or without lactose malabsorption. Nutrition; 4:131-5.

Esha A, Pavan B, Guruprasad CN, Savitha N, Pradeep AR (2011). Probiotics: A novel step towards oral health. Arch. Oral Sci Res; 1:108-115.

Flichy-Fernández AJ, Alegre-Domingo T, Peñarrocha-Oltra D, PeñarrochaDiago M (2010). Probiotic treatment in the oral cavity: An Update. J Med Oral Patol Oral Cir Bucal; 15:677680.

Franzosa E. A., Morgan, X. C., Segata, N., Waldron, L., Reyes, J., Earl, A. M., et al., (2014). Relating the metatranscriptome and metagenome 
of the human gut. Proc. Natl. Acad. Sci. U.S.A. 111, E2329-E2338. doi: 10.1073/pnas.1319284111

Galdeano CM, de Moreno de LeBlanc A, Vinderola G, Bonet ME, Perdigón G (2007). Praposed model: mechanisms of immunomodulation induced by probiotic bacteria. Clinical and Vaccine Immunology; 14:485-492.

Gill HS (1998). Stimulation of the immune system by lactic cultures. Int Dairy J; 8:535-44.

Gill HS, Cross ML, Rutherfurd KJ et al., (2001). Dietary probiotic supplementation to enhance cellular immunity in the elderly. $\mathrm{Br} \mathrm{J}$ Biomed Sci; 58:94-6.

Gill HS, Rutherfurd KJ, Gopal P, et al., (2001). Enhancement of immunity in the elderly by dietary supplementation with the probiotic Bifidobacterium lactis HN019. Am J Clin Nutr; 74:833-9.

Gosalbes M. J., Durbán, A., Pignatelli, M., Abellan, J. J., Jiménez-Hernández, N., Pérez-Cobas, A. E., et al., (2011). Metatranscriptomic approach to analyze the functional human gut microbiota. PLoS ONE 6:e17447. doi: 10.1371/journal.pone.0017447

Hatakka K, Ahola AJ, Yli-Knuuttila H, Richardson M, Poussa T, Meurman JK, et al., (2007). Probiotics reduce the prevalence of oral Candida in the elderly - a randomized controlled trial. J Dent Res.; 86:125-30.

Haukioja A (2010). Probiotics and Oral Health.Eur J Dentistry; 4:348-355.

He F, Tuomola E, Arvilommi $\mathrm{H}$, et al., (2000). Modulation of humoral immune response through probiotic intake. FEMS Immunol Med Microbiol; 29:47-52.

Hennequin C, Kauffmann-Lacroix C, Jobert
A, et al., (2000) Possible role of catheters in Saccharomyces boulardii fungemia. Eur J Clin Microbiol Infect Dis; 19:16 -20.

Houle MA, Grenier D (2003). Maladies parodontales: connaissances actuelles.Current concepts in periodontal diseases. Méd Mal Infect; 33: 331-40.

Jaddu Jyothirmai R, Naganandini S, Shankar A (2010). Probiotics in dentistry: review of the current status. Revista de clinica e pesquisaodontologica; 6:261-267.

Kang MS, Chung J, Kim SM, Yang KH, Oh JS (2006). Effect of Weissella cibaria isolates on the formation of Streptococcus mutans biofilm. Caries Res; 40: 418-25.

Kedar S, Shashikant MC, Priya T, Sultana N, Nallan CSK (2010). ProbioticsDo they have a role in Medicine and Dentistry. J. Assoc. Physicians of India; 58:488-492.

Kim HJ, Camilleri M, McKinzie S et al., (2003). A randomized controlled trial of a probiotic, VSL\#3, on gut transit and symptoms in diarrhoeapredominant irritable bowel syndrome. Aliment Pharmacol Ther; 17:895-904.

Kingsley C. Anukam, G. Reid (2007). Probiotics: 100 years (1907-2007) after Elie Metchnikoff's Observation. Communicating Current Research and Educational Topics and Trends in Applied Microbiology A. Méndez-Vilas (Ed.); 466-474.

Kolars JC, Levitt MD, Aouji M, et al., (1984). Yogurt—an autodigesting source of lactose. N Engl J Med; 310:1-3.

Kumar A, Vandana (2013). Probiotics: Nature's medicine. Int $\mathbf{J}$ Nutr Pharmacol Neurol Dis ;3:219-28 
Lichtman SM (2001). Bacterial translocation in humans. J Pediatr Gastroenterol Nutr; 33:1-10.

Lin SY, Ayres JW, Winkler W et al., (1989). Lactobacillus effects on cholesterol: in vitro and in vivo results. J Dairy Res; 72:2885-99.

Link-Amster H, Rochat F, Saudan KY et al., (1994). Modulation of a specific humoral immune response and changes in intestinal flora mediated through fermented milk intake. FEMS Immunol Med Microbiol; 10:55-64.

Loskutova IE (1985). Effectiveness of using maluitka and Malysh adapted propronic acidophilus mixtures in the combined treatment of congenital hypertrophy. Vopr Pitan; 17-20.

Lovegrove J, Jackson K (2003). Coronary heart disease. In: Mattila Sandholm T, Saarela M, eds. Functional dairy products. Cambridge, UK: Woodhill Publishing: 54-87.

Mackay AD, Taylor MB, Kibbler CC, Hamilton-Miller JM (1999). Lactobacillus endocarditis caused by a probiotic organism. Clin Microbiol Infect; 5:290 -2.

Majamaa H, Isolauri E (1997). Probiotics: a novel approach in the management of food allergy. J Allergy Clin Immunol; 99:179-85.

Majamaa H, Isolauri E, Saxelin M et al., (1995). Lactic acid bacteria in the treatment of acute rotavirus gastroenteritis. J Pediatr Gastroenterol Nutr; 20:333-8.

Mann GV, Spoerry A (1974). Studies of a surfactant and cholesteremia in the Maasai. Am J Clin Nutr; 27:464-9.

Marcobal A., Kashyap, P. C., Nelson, T. A., Aronov, P. A., Donia, M. S., Spormann, A., et al., (2013). A metabolomic view of how the human gut microbiota impacts the host metabolome using humanized and gnotobiotic mice. ISME J. 7, 1933-1943. doi: 10.1038/ismej.2013.89

Meurman JH. Probiotics:do they have a role in oral medicine and dentistry (2005). Eur J Oral Sci; 113(3):18896.

Meydani SN, Ha WK (2000). Immunologic effects of yogurt. Am J Clin Nutr; 71:861-72.

Narwal A, Shashi Bala (2011). Probiotics in Dentistry - A Review. J Nutr Food Sci 1:114. doi: $10.4172 / 2155-$ 9600.1000114

Nicole MR, Martjin BK (2000). Effects of probiotic bacteria on diarrhea, lipid metabolism and carcinogenesis: a review of papers published between 1988 and 1998. Am J of Clin Nutr;71:405-411

Nicole MR, Martjin BK (2000). Effects of probiotic bacteria on diarrhea, lipid metabolism and carcinogenesis: a review of papers published between 1988 and 1998. Am J of Clin Nutr ;71:405-411

Nikawa H, Makihira S, Fukushima H, Nishimura H, Ozaki K, Ishida K, et al., (2004). Lactobacillus reuteri in bovine milk fermented decreases the oral carriage of mutans streptococci. Int J Food Microbiol; 95: 219-23.

Nobaek S, Johansson ML, Molin G et al., (2000). Alteration of intestinal microflora is associated with reduction in abdominal bloating and pain in patients with irritable bowel syndrome. Am J Gastroenterol; 95:1231-8.

Okawa T, NiibeH, Arai T et al., (1993). Effect of LC 9018 combined with radiation therapy on carcinoma of the uterine cervix. Cancer; 72: 194954. 
Olah A, Belagyi T, Issekutz A et al., (2002). Randomized clinical trial of specific lactobacillus and fibre supplement to early enteral nutrition in patients with acute pancreatitis. Br J Surg; 89:1103-7.

Patil MB, Reddy N. Bacteriotherapy and probiotics in dentistry (2006). KSDJ; 2:98-102.

Pradeep K, Kuttapa MA, PrassanaRao (2012). Probiotics and oral health: An update. Bio Med Rep; 2:246252.

Prashanthi R, Rajeev S (2011). Probiotics the next savior in oral disease. Intl J. dental clinics; 3:54-57.

Rajasekaran A, Sivagnanam G, Xavier R (2008). Nutraceuticals as therapeutic agents: A Review. ResJ. Pharm. \& Tech.; 1: 328-340.

Rastogi P, Saini H, Dixit J, Singhal R (2011). Probiotics and oral health. Natl J Maxillofac Surg;2:6-9

Rautio M, Jousimies-Somer H, Kauma H, et al., (1999). Liver abscess due to a Lactobacillus rhamnosus strain indistinguishable from $L$. rhamnosus strain GG. Clin Infect Dis; 28:115960.

Rayes N, Seehofer D, Hansen S et al., (2002). Early enteral supply of lactobacillus and fiber versus selective bowel decontamination: a controlled trial in liver transplant recipients. Transplantation; 74:1237.

Reddy BS, Riverson A (1993). Inhibitory effect of B ongum on colon, mammary and liver carcinogenesis induced by 2 amino-3methylimidazo (4, 5-+) quinoline, a food mutagen. Cancer Res; 53: 3914-8.

Reid G, Bruce AW, Fraser N et al., (2001). Oral probiotics can resolve urogenital infections. FEMS Immunol Med Microbiol; 30: 49-52.

Reid G, Bruce AW, Taylor M (1995). Instillation of Lactobacillus and stimulation of indigenous organisms to prevent recurrence of urinary tract infections. Microecology Therapy; 23: 32-45.

Reid G, Charbonnaeau D, Erb J et al., (2003). Oral use of Lactobacillus rhamnosus GR-1 and L. Fermentum RC-14 significantly alters vaginal flora: randomised placebo controlled trial in 64 healthy women. FEMS Immunol Med Microbiol; 35: 131-4.

Rinkee M, Bianca N, Neha S (2011). The potential role of probiotics in periodontal health. RSBO Revista Sul-Brasileira de Odontologia; 9: 8588.

Saavedra JM, Bauman NA, Oung I, et al., (1994). Feeding of Bifidibacterium bifidum and Streptococcus thermophilus to infants in hospital for prevention of diarrhoea and shedding of rotavirus. Lancet; 344:1046-9.

Schiffrin EJ, Rochar F, Link-Amster H, et al., (1995). Immunomodulation of human blood cells following the ingestion of lactic acid bacteria. $\mathbf{J}$ Dairy Sci; 78:491-7.

Schrezenmeir J, de Verse M (2001). Probiotics, prebiotics, and synbiotics- approaching a definition. Am J Clin Nutr; 73:361S-364S.

Sekine K, Watanabe - Sekine E, Ohta J et al., (1994). Induction and activation of tumoricidal cells in vitro and (in vivo by the bacterial cell wall of $B$ infants). Bifidobacteria and Microflora; 13: 54-77.

Singh VP, Sharma J, Babu S, Rizwanulla ,Singla A (2013). Role of probiotics in health and diseases: A review. $\mathrm{J}$ Pak Med Assoc; 63:253-257. 
Soccol C R, de Souza Vandenberghe L.P., Spier M.R., Medeiros A.B.P., Yamaguishi C.T., De Dea Lindner, Pandey J., A. and Thomaz-Soccol V. (2010). The Potential of Probiotics: A Review. Food Technol. Biotechnol. 48 (4): 413-434.

Sumit N, Ruby G, Anu N (2011). Probiotics in oral health care- A Review. Intl. J. scientific engineering; 2:39-43.

Sutas Y, Hurme M, Isolauri (1996). Downregulation of anti-Co3 antibody induced IL-4 production by bovine caseins hydrolysed with LGG derived enzymes. Scand J Immunol; 98: 216-24.

Tiwari G, Tiwari R, Pandey S, Pandey P (2012). Promising future of probiotics for human health: Current scenario. Chron Young Sci; 3:17-28.

Trapp CL, Charg CC, Halpern GM et al., (1993). The influence of chronic yogurt consumption on population of young and elderly adults. Int $J$ Imunother; 9: 53-64.
Van't Veer P, Dekker JM, Lamers JWJ, et al., (1989). Consumption of fermented milk products and breast cancer: a case-control study in the Netherlands. Cancer Res; 49:40203.

Vineet A, Sonali K, Nimisha S (07/2012). Role of 'Live Microoranisms' (probiotics) in prevention of caries: Going on the natural way towards oral health. Ind J. Multidisciplinary Dentistry; 2(3):491-496.

Vishnu HP (2012). Probiotics and oral health, oral health care- Pediatric, Research, Epidemiology, and clinical Practices. INTECH; 195204.

Wendakoon CN, Thomson AB, Ozimek L (2002). Lack of therapeutic effect of a specially designed yogurt for the eradication of Helicobacter pylori infection. Digestion; 65:16-20.

Yasui H, Nagaoka N, Mike A et al., (1992). Detections of bifidobacterium strains that induce large quantities of $\operatorname{IgA}$. Microb Ecol Health Dis; 5: 155-62.

\section{How to cite this article:}

Sameer Singh Faujdar, Priya Mehrishi, Surabhi Bishnoi and Amisha Sharma. 2016. Role of Probiotics in human health and disease: An update. Int.J.Curr.Microbiol.App.Sci. 5(3): 328344. doi: http://dx.doi.org/10.20546/ijcmas.2016.503.040 